\title{
Estudo das propriedades físico-químicas e avaliação da toxicidade aguda do extrato etanólico das folhas de Mikania glomerata Sprengel
}

SANTANA, L.C.L.R.'; BRITO, M.R.M.'; SOUSA, G.F.'; FREITAS, R.M.1

'Laboratório de Pesquisa em Neuroquímica Experimental do Programa de Pós-graduação em Ciências Farmacêuticas, Centro de Ciências da Saúde, Campus Ministro Petrônio Portela, CEP: 64.049-550, Teresina - Brasil. *rivelilson@pq.cnpq.br

RESUMO: A Mikania glomerata é uma planta pertencente à família Asteraceae que é bastante utilizada na medicina popular devido às suas ações broncodilatadora, antiasmática, expectorante e antitussígena. $O$ objetivo do presente estudo foi determinar as propriedades físico-químicas do pó obtido a partir das folhas de M. glomerata, bem como, avaliar a toxicidade em camundongos após tratamento agudo com doses repetidas do extrato etanólico padronizado preparado a partir das folhas dessa espécie. Durante o estudo das propriedades físico-químicas do pó obtido a partir das folhas de M. glomerata foram feitas as determinações da densidade bruta e de compactação, do teor de cinzas totais, do teor de umidade, e da granulometria. De acordo com os resultados obtidos podemos sugerir que o pó pode ser usado na formulação de uma forma farmacêutica sólida. Na segunda parte do estudo foi determinada a Dose Letal $50 \%\left(\mathrm{DL}_{50}\right)$, bem como, realizada a análise morfológica macroscópica e avaliados a toxicidade aguda com doses repetidas e os parâmetros bioquímicos e hematológicos de camundongos. De acordo com os dados obtidos na segunda parte deste estudo podemos sugerir que o extrato etanólico pode ser usado de forma segura em humanos, uma vez que apresentou valor de $\mathrm{DL}_{50}$ de aproximadamente $3000 \mathrm{mg} \mathrm{Kg}^{-1}$ ), bem como, não produziu nenhuma alteração morfológica nos principais órgãos, e nem provocou alterações nos parâmetros bioquímicos e hematológicos de camundongos.

Palavras-chave: Mikania glomerata, Asteraceae, Toxicidade Aguda, Camundongos.

\begin{abstract}
Study of the physicochemical properties and acute toxicity evaluation of the ethanolic extract of the leaves of Mikania glomerata Sprengel. The Mikania glomerata is a plant belonging to the Asteraceae that is widely used in folk medicine because of its bronchodilator, antiasthmatic, expectorant and antitussive actions. The aim of this study was to determine the physicochemical properties of the powder obtained from the leaves of $M$. glomerata, and to evaluate its toxicity in mice after acute treatment with repeated doses of standardized ethanol extract prepared from the leaves of this plant species. We determined the bulk and packing density, the total ash content, the moisture content and the particle size. The results suggest that the powder can be used in the formulating of a solid pharmaceutical form. In the second part of this study, we determined the $50 \%$ lethal dose (LD50), performed the gross morphological analysis and evaluated the acute toxicity from the use of repeated doses and the biochemical and hematologic parameters in mice. The data obtained in this part suggest that the ethanol extract can be used safely in humans, since it has a LD50 value of approximately $3000 \mathrm{mg} \mathrm{kg}-1$ and produced no morphological changes in the major organs, or caused alterations in the biochemical and hematological parameters in mice.
\end{abstract}

Keywords: Mikania glomerata, Asteraceae, Acute toxicity, Mice.

\section{INTRODUÇÃO}

A Mikania glomerata é uma trepadeira pertencente à família Asteraceae que tem folhas opostas, ovais, simples e acuminadas, e flores brancas (Teske \& Trentini,1997). Asteraceae é uma das maiores famílias das Angiospermas com aproximadamente 1535 gêneros e 23.000 espécies (Bremer, 1994). O gênero Mikania Willd. conhecido popularmente como Guaco, caracteriza- 
se por plantas herbáceas, anuais ou perenes, subarbustivas e escandentes (Pio Corrêa, 1984).

É uma planta conhecida popularmente por vários nomes, dentre eles: guaco trepador, guacode-cheiro, guaco liso, erva de cobra, cipó catinga, e coração de Jesus (Celeghini et al., 2001) sendo Guaco o nome mais utilizado na região nordeste.

A espécie é originária da América do Sul ocorrendo espontaneamente no Brasil e também no Uruguai, na Argentina e no Paraguai (Celeghini et al., 2001). No Brasil, ocorre de norte a sul, tendo como principal área de dispersão os estados de Minas Gerais, Rio de Janeiro e São Paulo (Oliveira, 1972; Ritter \& Miotto, 2005).

M. glomerata Sprengel é uma planta<smiles>O=c1ccc2ccccc2o1</smiles>

(A)<smiles>C=C(C)C1CCC2(C)CC[C@H]3C(CCC4C5(C)CCC(O)C(C)(C)C5CCC43C)C12</smiles>

(B)

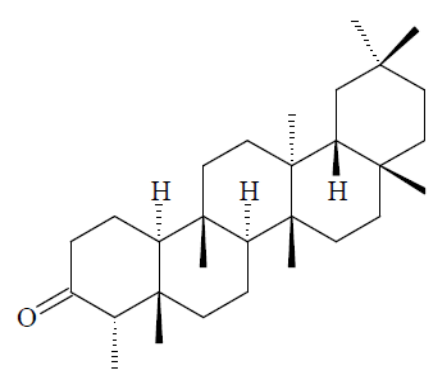

(C)

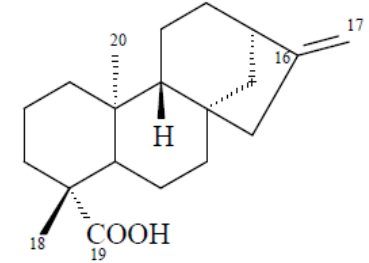

(D)

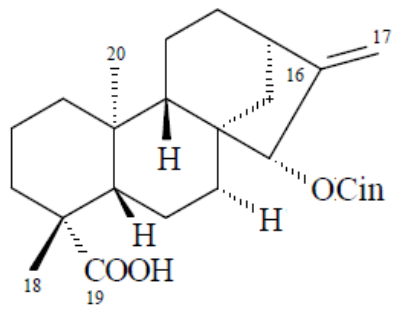<smiles>[CH2]C(=O)/C=C/c1ccccc1</smiles>

(E)

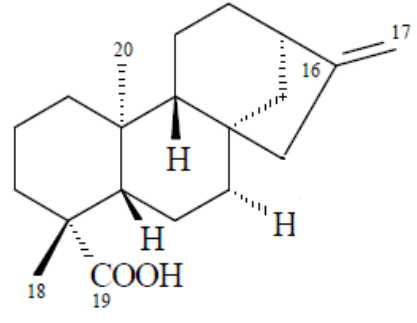

$(\mathrm{H})$

$(\mathrm{K})$

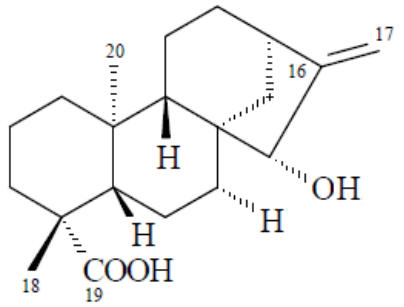<smiles>CCC(/C=C/C(C)C1CCC2C3CC=C4CC(O)CCC4(C)C3CCC12C)C(C)C</smiles>

(F)

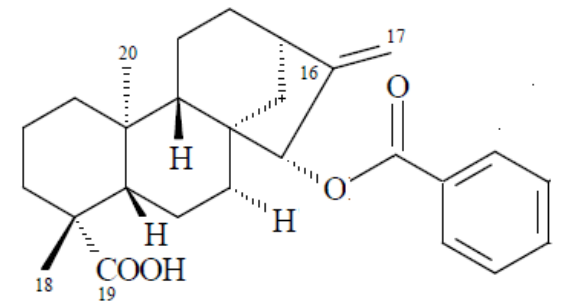

(J)<smiles>O=C(O)C=Cc1ccccc1O</smiles>

(M)
$(\mathrm{L})$

Rev. Bras. PI. Med., Campinas, v.16, n.3, supl. I, p.670-678, 2014. 
Vários estudos científicos comprovam as atividades farmacológicas da M. glomerata Sprengel como bactericida, antiofídica, antialérgica, antifúngica, antiinflamatória, antidiarréica, inibidora da enzima MAO (monoamino oxidase), antimalárica, antioxidante, anti-helmíntica, ansiolítica e broncodilatadora (Fierro et al., 1999; Holetz et al., 2002; Soares et al., 2002; Do Amaral et al., 2003; Falcão et al., 2005; Maiorano et al., 2005; Salgado et al., 2005; Santos et al., 2006; Santana, et al. 2013a; Santana et al., 2013b; Botsaris, 2007). O objetivo do presente estudo foi determinar as propriedades físico-químicas do pó obtido a partir das folhas de $M$. glomerata, bem como avaliar a toxicidade em camundongos após tratamento agudo com doses repetidas do extrato etanólico padronizado preparado a partir das folhas dessa espécie.

\section{MATERIAL E MÉTODOS}

\section{Preparação da droga utilizada nos tratamentos}

\section{Material Vegetal}

A parte aérea de M. glomerata foi coletada no Horto de Plantas Medicinais do Núcleo de Fitoterapia (NUFITO), que faz parte do Núcleo de Assistência Farmacêutica (NUASF) da Secretaria de Saúde do Estado do Ceará (SESA). A exsicata (número 27.041) foi depositada no Herbário Graziella Barroso da Universidade Federal do Piauí. O material foi colhido manualmente e lavado em água corrente, seguido de lavagem em água destilada. Após a pesquisa de materiais estranhos, a matéria-prima vegetal foi seca à sombra.

\section{Preparação do extrato etanólico} padronizado das folhas de M. glomerata O extrato foi preparado com maceração prévia por $24 \mathrm{~h}$ em solução hidro-alcoólica a $70 \%$, seguindo-se em percolação na proporção de 15 $\mathrm{mL}$ de extrato para cada $1 \mathrm{~g}$ de droga vegetal. A solução extrativa foi então concentrada em estufa com circulação forçada de ar para eliminar o teor alcoólico e aumentar o teor de sólidos, reduzindo o volume inicial em $75 \%$. A solução extrativa foi evaporada e o resíduo foi dissolvido em solução salina $0,9 \%$.

\section{Estudo das propriedades físico-químicas do pó obtido a partir das folhas de $M$. glomerata \\ Determinação da granulometria \\ A determinação da granulometria (tamanho das partículas do pó e distribuição de tamanho)}

foi realizada seguindo a metodologia prevista na Farmacopéia Brasileira (1988). O procedimento foi desenvolvido mecanicamente usando agitador com movimentos horizontais e verticais e empregando-se tamises padronizados e superpostos, partindo-se do maior para o menor diâmetro. Porção de $30 \mathrm{~g}$ foi colocada no tamis de maior malha e submetida à tamisação durante 30 minutos.

\section{Determinação da densidade bruta e de compactação \\ Esses ensaios seguiram as metodologias} propostas por Guo e colaboradores (1985) e Cardoso (2002). A amostra foi colocada em provetas previamente pesadas. A densidade de compactação foi determinada com auxílio de volúmetro de compactação. $O$ pó foi submetido a 1250 quedas, segundo a norma DIN 53194. Após essas determinações calculou-se o fator de Hausner determinado através do quociente entre as densidades compactada $(d c)$ e bruta $(d b)$ (Aulton, 2005). O índice de compressibilidade (IC) foi determinado segundo equação $(d c-d b) / d c$ (Wanczinski, 2002).

\section{Determinação do teor de cinzas totais}

A amostra foi reduzida a pó semi-fino, pesada, e transferida para cadinho previamente calcinado, resfriado e pesado. Foi levada à ignição a temperatura de $675 \pm 25^{\circ} \mathrm{C}$ (The United States Pharmacopeia, 2007) em forno mufla até que todo o material fosse eliminado. A amostra foi resfriada em dessecador e pesada. Foi calculado a porcentagem de cinzas em relação à droga seca à sombra.

\section{Determinação do teor de umidade}

A amostra foi reduzida a pó fino. Foi pesado exatamente $1 \mathrm{~g}$ da amostra e transferida para pesa-filtro chato previamente dessecado durante 30 minutos nas mesmas condições a serem empregadas na determinação. Foi pesado o pesa-filtro, tampado, contendo a amostra. O pesa-filtro foi agitado brandamente para distribuir a amostra de maneira mais uniforme possível a uma profundidade ideal de $5 \mathrm{~mm}$. O pesa-filtro foi colocado na estufa, sua tampa foi removida, deixando-a também na estufa. A amostra foi secada a temperatura de $105^{\circ} \mathrm{C}$ e por 2 horas. Em seguida foi resfriada a temperatura ambiente em dessecador, e posteriormente pesada. A operação foi repetida até a obtenção de peso constante (The United States Pharmacopeia, 2007).

Determinação da dose letal $50 \%\left(\mathrm{DL}_{50}\right)$ e da toxicidade aguda do extrato etanólico das folhas de M. glomerata

Setenta camundongos, sendo 35 machos

Rev. Bras. PI. Med., Campinas, v.16, n.3, supl. I, p.670-678, 2014. 
e 35 fêmeas foram divididos em 7 grupos de 10 animais cada. Os animais foram tratados por via oral durante 30 dias com doses de 200, 300, 400, 500, 1000, 2000 e $3000 \mathrm{mg} \mathrm{Kg}^{-1}$ do extrato etanólico padronizado das folhas de $M$. glomerata. Durante o período de tratamento foram realizadas observações comportamentais sistemáticas para avaliar o screening hipocrático que fornece uma estimativa geral da toxicidade da substância sobre o estado de consciência e disposição geral, atividade e coordenação do sistema motor, reflexos e atividades sobre os sistemas nervoso central e autônomo (Malone \& Robichaud, 1983). Os parâmetros (atividade geral, frênito vocal, irritabilidade, resposta ao toque, contorção, reflexo de endireitamento, tônus muscular, força para agarrar, ataxia, reflexo auricular, reflexo corneal, tremores, convulsões, calda em straub, hipnose, anestesia, lacrimação, ptose palpebral, micção, defecação, piloereção, hipotermia, respiração, cianose, hiperemia, morte) foram avaliados durante o período de 30 dias, sendo avaliados a cada dois dias e, a partir de então, diariamente, até o último dia de administração do extrato. Sinais de toxicidade, a época do seu aparecimento, a intensidade, a duração e a progressão dos mesmos foram anotados para posterior análise.

Os animais sobreviventes foram eutanasiados com pentobarbital sódico $40 \mathrm{mg} \cdot \mathrm{Kg}^{-1}$, conforme protocolo da Cornell University/Cornell Center for Animal Resources and Education, conforme descrito por Flecknell (1996) e Kohn e colaboradores (1997), e eutanasiados por deslocamento cervical. Foram observados e registrados, diariamente, dados fisiológicos (peso corpóreo, consumo de água, consumo de ração, produção de excretas) e alterações comportamentais anormais durante todo o estudo (Cunha et al., 2009).

O número de mortes de cada grupo foi expresso em relação ao número total de animais que receberam o produto por grupo. A determinação da dose letal $50 \%\left(\mathrm{DL}_{50}\right)$ foi feita através da interpolação semi-logarítmica, sendo postos no eixo das ordenadas os valores dos probitos correspondentes ao percentual de mortes e, no eixo das abcissas, as doses administradas do produto.

\section{Análise dos parâmetros bioquímicos e hematológicos}

Quarenta camundongos, sendo 20 machos e 20 fêmeas foram divididos em 4 grupos de 10 animais cada. Os animais foram tratados diariamente por via oral durante 30 dias com o veículo (Tween 80 0,05\% dissolvido em solução salina 0,9\%; grupo controle) e com as doses de 200, 300 e $400 \mathrm{mg} \mathrm{Kg}^{-1}$ do extrato etanólico padronizado das folhas de $M$. glomerata. Após 30 dias de tratamento os animais foram anestesiados com pentobarbital sódico (40 $\mathrm{mg} \mathrm{Kg}^{-1}$, i.p.) e a coleta do sangue foi realizada por punção do plexo venoso orbital, utilizando-se agulhas e seringas e tubos de microhematócrito. $O$ sangue foi acondicionado em dois tipos de tubo: um com anticoagulante HB (Laborlab ${ }^{\circledR}$ ) para determinação dos parâmetros hematológicos, e o outro, sem anticoagulante, para obtenção do soro para avaliação dos parâmetros bioquímicos.

Os valores para eritrócitos, leucócitos, plaquetas, hemoglobina, hematócrito e os índices hematimétricos volume corpuscular médio (VCM), hemoglobina corpuscular média (HCM) e concentração de hemoglobina corpuscular média (CHCM) foram determinados imediatamente após a coleta por meio de um analisador automático de células hematológicas Advia 120/Hematology Siemens. A contagem diferencial de leucócitos foi realizada em extensões coradas com MayGrünwald-Giemsa. Em cada ensaio, 100 células foram analisadas e contadas.

Para análise bioquímica, o material foi centrifugado a $3500 \mathrm{rpm}$ durante 10 minutos e, em seguida, determinados os parâmetros glicose, uréia, creatinina, aspartato aminotransferase (AST), alanina aminotransferase (AST), colesterol total, triglicerídeos, fosfatase alcalina (ALP), bilirrubinas total e direta, proteínas totais e ácido úrico. Os ensaios foram realizados em aparelho automático Labmax 240 (Labtest) com sistemas comerciais da Labtest ${ }^{\circledR}$.

\section{Análise morfológica macroscópica}

Após a eutanásia, a avaliação macroscópica foi realizada à vista desarmada dos órgãos, além da pesagem de fígado, pulmão, coração, rim, cérebro e baço para determinar os pesos relativos e verificar se houve ou não alteração morfológica macroscópica nos principais órgãos avaliados. O trabalho foi aprovado pelo Comitê de ética em Experimentação com Animais (\#050/2010).

\section{Análises estatísticas}

Os valores foram expressos como média \pm erro padrão da média (E.P.M.). As diferenças entre os grupos foram determinadas por meio da Análise de Variância (ANOVA), seguida, quando detectada diferença, pelo teste $t$-Student-Newman-Keuls como post hoc teste. O nível de significância para rejeição da hipótese de nulidade foi sempre $\geq$ a $5 \%$.

\section{RESULTADOS E DISCUSSÃO}

\section{Estudo das propriedades físico-químicas do pó obtido das folhas de M. glomerata}

No estudo das propriedades físico-químicas foi verificada em triplicata, a densidade bruta (0.2105

Rev. Bras. PI. Med., Campinas, v.16, n.3, supl. I, p.670-678, 2014. 
$\left.\mathrm{g} \mathrm{ml}^{-1}\right)$ e de compactação $\left(0.2757 \mathrm{~g} \mathrm{ml}^{-1}\right)$ do pó obtido das folhas de $M$. glomerata que corresponde ao Fator de Hausner de 1.30. O valor de cinzas totais foi de $1,174 \%$, enquanto o teor de umidade foi de $12.33 \%$. A granulometria correspondeu ao diâmetro médio de 97,8 $\mu \mathrm{m}$. Com base nesses resultados podemos sugerir que não haverá problemas durante a compressão devido a propriedades de fluidez do pó obtido das folhas do material vegetal estudado (Staniforth, 2005; Prescott \& Barnum, 2000).

\section{Toxicidade aguda}

O extrato de $M$. glomerata não alterou a massa corpórea dos animais. Durante o tratamento não foram observados sinais clínicos de toxicidade nas doses de 200, 300, 400 e $500 \mathrm{mg} \mathrm{Kg}^{-1}$ e o registro de morte ocorreu a partir da dose de 1000 $\mathrm{mg} \mathrm{Kg}^{-1}$ apresentando, por via oral, a dose letal de $50 \%\left(\mathrm{DL}_{50}\right)$ de $3000 \mathrm{mg} \cdot \mathrm{Kg}^{-1}$. Não houve alteração no consumo de água e ração entre os animais acompanhados durante os 30 dias (Tabela 1).

Segundo latsyno (1978) o acompanhamento da massa corpórea do animal é um importante indicador para a avaliação da toxicidade de uma substância. O tratamento com o extrato de $M$. glomerata durante 30 dias por via oral não alterou o ganho de massa corporal dos camundongos, bem como não foi verificado alteração no consumo de água e ração.

\section{Parâmetros bioquímicos}

$\mathrm{Na}$ análise dos parâmetros bioquímicos para avaliar a toxicidade aguda, não foi verificado alteração na concentração sanguínea de creatinina entre os animais dos grupos tratados com extrato de M. glomerata nas doses de 200 e $300 \mathrm{mg} \mathrm{kg}^{-1}$ em comparação ao grupo controle. Por outro lado, a dose de $400 \mathrm{mg} \mathrm{Kg}^{-1}$ do extrato promoveu aumento de $60 \%$ nos níveis de creatinina quando comparado ao grupo controle. Os níveis de uréia dos grupos tratados com as mesmas doses (200, 300 e 400 $\mathrm{mg} \mathrm{kg}^{-1}$ ) resultou em redução de 29,3, 20,3 e 62,7\%, respectivamente, em comparação ao grupo controle.

Dessa forma, considerando que apenas na dose de $400 \mathrm{mg} \mathrm{Kg}^{-1}$ podem ocorrer pequenas modificações na concentração da creatinina, e devido a ausência de alterações nos níveis da uréia sugere-se que o extrato de $M$. glomerata possa produzir apenas alterações primárias das condições renais e sem importância clínica.

Podemos verificar também alteração nos níveis de triglicerídeos e de colesterol total nos grupos tratados com o extrato de $M$. glomerata nas doses de 200, 300 e $400 \mathrm{mg} \mathrm{kg}^{-1}$ em comparação ao grupo controle, havendo redução em ambos os níveis. Por sua vez nos níveis de triglicerídeos a redução foi de $34,2,18,8$ e 34,8\%, respectivamente. Nos níveis de colesterol total a redução foi de 19,3, 20,2 e $17,7 \%$, respectivamente para as doses avaliadas do extrato.

Durante a avaliação da toxicidade aguda também foi determinado o nível sanguíneo de ácido úrico em camundongos tratados com o extrato de M. glomerata nas doses de 200, 300 e $400 \mathrm{mg} \mathrm{kg}^{-1}$ por via oral. Foi verificada alteração na concentração sanguínea de ácido úrico caracterizada por redução de 66,6, 96,2 e 65,9\%, respectivamente, em comparação ao grupo controle, sugerindo que o extrato de $M$. glomerata pode não induzir o desenvolvimento de cálculo renal, uma vez que não

TABELA 1. Toxicidade aguda após tratamento com doses repetidas do extrato etanólico de M. glomerata em camundongos.

\begin{tabular}{|c|c|c|c|c|c|}
\hline \multirow{2}{*}{$\begin{array}{c}\text { Dose } \\
\left(\mathrm{mg} \mathrm{kg}^{-1}\right)\end{array}$} & \multicolumn{3}{|c|}{ Animais } & \multirow{2}{*}{\multicolumn{2}{|c|}{ Latência de Morte Sintomas de toxicidade }} \\
\hline & n/Dose & Sexo & $\mathrm{D} / \mathrm{T}$ & & \\
\hline \multirow[t]{2}{*}{200} & 5 & Fêmeas & $0 / 5$ & - & Nenhum \\
\hline & 5 & Machos & $0 / 5$ & - & Nenhum \\
\hline \multirow[t]{2}{*}{300} & 5 & Fêmeas & $0 / 5$ & - & Nenhum \\
\hline & 5 & Machos & $0 / 5$ & - & Nenhum \\
\hline \multirow[t]{2}{*}{400} & 5 & Fêmeas & $0 / 5$ & - & Nenhum \\
\hline & 5 & Machos & $0 / 5$ & - & Nenhum \\
\hline \multirow[t]{2}{*}{500} & 5 & Fêmeas & $0 / 5$ & - & Nenhum \\
\hline & 5 & Machos & $0 / 5$ & - & Nenhum \\
\hline \multirow[t]{2}{*}{1000} & 5 & Fêmeas & $1 / 5$ & $<12 \mathrm{~h}$ & Nenhum \\
\hline & 5 & Machos & $0 / 5$ & $<12 \mathrm{~h}$ & Nenhum \\
\hline \multirow[t]{2}{*}{2000} & 5 & Fêmeas & $2 / 5$ & $<12 \mathrm{~h}$ & Contorções abdominais, taquicardia \\
\hline & 5 & Machos & $0 / 5$ & $<12 \mathrm{~h}$ & Contorções abdominais, taquicardia \\
\hline \multirow[t]{2}{*}{3000} & 5 & Fêmeas & $5 / 5$ & $<12 \mathrm{~h}$ & Contorções abdominais, taquicardia e piloereção \\
\hline & 5 & Machos & $0 / 5$ & $<12 \mathrm{~h}$ & Contorções abdominais, taquicardia e piloereção \\
\hline
\end{tabular}

MK= Extrato etanólico padronizado de $M$. glomerulata; $n /$ dose = número de animais por dose; $D=$ número de mortes; $T=$ número de animais tratados;

Rev. Bras. PI. Med., Campinas, v.16, n.3, supl. I, p.670-678, 2014. 
TABELA 2. Parâmetros bioquímicos obtidos do soro de camundongos Swiss, tratados com o extrato etanólico padronizado de M. glomerata por via oral durante 30 dias.

\begin{tabular}{lcccc}
\hline Parâmetros & $\begin{array}{c}\text { Controle } \\
(\mathbf{n = 1 0 )}\end{array}$ & $\begin{array}{c}\text { MG 200 } \\
(\mathbf{n = 1 0})\end{array}$ & $\begin{array}{c}\text { MG 300 } \\
(\mathbf{n = 1 0})\end{array}$ & $\begin{array}{c}\text { MG 400 } \\
(\mathbf{n = 1 0})\end{array}$ \\
\hline Glicose $\left(\mathrm{mg} \mathrm{dL}^{-1}\right)$ & $93,14 \pm 1,47$ & $95,50 \pm 1,32$ & $92,09 \pm 2,07$ & $96,70 \pm 1,93$ \\
Uréia $\left(\mathrm{mg} \mathrm{dL}^{-1}\right)$ & $54,67 \pm 0,30$ & $38,70 \pm 3,80$ & $43,60 \pm 4,44$ & $20,40 \pm 1,54$ \\
Creatinina $\left(\mathrm{mg} \mathrm{dL}^{-1}\right)$ & $0,43 \pm 0,43$ & $0,47 \pm 0,31$ & $0,47 \pm 0,58$ & $0,69 \pm 0,94$ \\
Ácido úrico $\left(\mathrm{mg} \mathrm{dL}^{-1}\right)$ & $2,61 \pm 0,04$ & $0,87 \pm 0,12$ & $0,10 \pm 0,09$ & $0,89 \pm 0,09$ \\
Triglicerídeos $\left(\mathrm{mg} \mathrm{dL}^{-1}\right)$ & $106,7 \pm 0,05$ & $70,20 \pm 6,07$ & $86,60 \pm 7,83$ & $69,50 \pm 7,24$ \\
CT $\left(\mathrm{mg} \mathrm{dL}^{-1}\right)$ & $82,35 \pm 2,47$ & $66,50 \pm 4,49$ & $65,80 \pm 4,79$ & $67,80 \pm 4,85$ \\
Proteínas totais $\left(\mathrm{mg} \mathrm{dL}^{-1}\right)$ & $6,10 \pm 0,25$ & $5,60 \pm 0,13$ & $5,90 \pm 0,12$ & $6,32 \pm 0,23$ \\
AST $\left(\mathrm{U} \mathrm{mL}^{-1}\right)$ & $90,33 \pm 2,09$ & $83,40 \pm 3,01$ & $93,60 \pm 2,93$ & $95,10 \pm 5,32$ \\
ALT $(\mathrm{U} \mathrm{mL-1})$ & $61,34 \pm 1,43$ & $46,90 \pm 1,86$ & $46,60 \pm 4,18$ & $65,00 \pm 4,21$ \\
Fosfatase alcalina $\left(\mathrm{U} \mathrm{L}^{-1}\right)$ & $157,60 \pm 0,97$ & $106,10 \pm 1,30$ & $113,40 \pm 4,71$ & $126,50 \pm 4,54$ \\
Bilirrubina total $\left(\mathrm{mg} \mathrm{dL}^{-1}\right)$ & $0,26 \pm 0,02$ & $0,15 \pm 0,06$ & $0,05 \pm 0,02$ & $0,31 \pm 0,03$ \\
Bilirrubina direta $\left(\mathrm{mg} \mathrm{dL}^{-1}\right)$ & $0,15 \pm 0,01$ & $0,01 \pm 0,00$ & $0,02 \pm 0,00$ & $0,21 \pm 0,03$ \\
\hline
\end{tabular}

Legenda: Parâmetros bioquímicos obtidos do soro de camundongos machos Swiss, tratados por via oral com solução salina $0,9 \%$ (Controle, $n=10$ ) e com extrato etanólico de M. glomerata (MG) nas doses 200 mg kg-1 (MG 200, $n=10$ ), 300 mg kg-1 (MG 300, $n=10$ ) e 400 mg kg-1 (MG 400, $n=10$ ) durante 30 dias. Os valores representam a média + E.P.M. do número de animais usados nos experimentos. $n-$ representa o número de animais em cada grupo. ap $<0,05$, quando comparados ao grupo controle (ANOVAe teste t Student-Newman-Keuls como post hoc test);

alterou o metabolismo do ácido úrico nos rins.

O hemograma é um exame laboratorial que permite avaliar de forma quantitativa e qualitativa os elementos figurados do sangue. É composto pelo eritrograma, leucograma e palquetograma. No eritrograma é executado a contagem de eritrócitos, a dosagem de hemoglobina, a determinação do hematócrito, o volume corpuscular médio (VCM), o hemoglobina corpuscular média (HCM), a concentração de hemoglobina corpuscular média (CHCM), e a amplitude de distribuição dos eritrócitos. Esses parâmetros foram observados no presente trabalho visando identificar possíveis correlações. Pose-se observar uma alteração significativa entre esses valores, uma vez que para o valor do VCM houve aumento de 18,5, 21,7 e 13\% em relação ao grupo controle, nos grupos tratados com o extrato de M. glomerata nas doses de 200, 300 e $400 \mathrm{mg}$ $\mathrm{kg}^{-1}$, respectivamente (Tabela 3).

No eritrograma avalia-se o eritrônio, cuja função é o transporte de oxigênio do pulmão aos tecidos, podendo ser exercido pelo conteúdo hemoglobínico, sendo sua fisiopatologia essencialmente quantitativa. Assim, a insuficiência funcional do eritrônio, anemia, é definida como a diminuição da hemoglobina sanguínea; esta costuma acompanhar-se, mas não necessariamente de modo paralelo, da diminuição do número de eritrócitos (Failace, 2009). Já a HCM, apresentou aumento de $46,4 \%$ com os grupos tratados nas doses de 200 e $300 \mathrm{mg} \mathrm{kg}^{-1}$ em relação ao grupo controle, e de $36,7 \%$ na dose de $400 \mathrm{mg} \mathrm{kg}^{-1}$ (Tabela 3).
Por fim, após o tratamento durante 30 dias por via oral com o extrato de $M$. glomerata nas doses de 200, 300 e $400 \mathrm{mg} \mathrm{kg}^{-1}$ não foram verificadas mudanças no perfil hematológico entre os camundongos (Tabela 3).

$\mathrm{Na}$ avaliação da análise morfológica macroscópica não houve alteração em nenhum dos órgãos avaliados (Tabela 4). De acordo com a literatura o extrato hidro-alcoólico de partes aéreas da mesma espécie não demonstrou efeitos tóxicos, uma vez que não houve alteração do peso corpóreo e dos principais órgãos de ratos Wistar (Sá et al. 2003).

Por outro lado, em um estudo realizado por Graça (2004) com extrato etanólico da espécie Mikania laevigata Schultz Bip. Ex Baker, pertencente ao mesmo gênero da espécie estudada, foram observadas alterações morfológicas macroscópicas do tipo fibrose pulmonar e dilatação pielocalicial renal em animais tratados com uma única dose da solução ou do xarope de partes aéreas de $M$. laevigata. Nesse mesmo estudo também foram observados alterações na massa relativa dos rins e do fígado.

Dessa forma, os resultados obtidos na avaliação da toxicidade aguda demonstra que o extrato etanólico padronizado das folhas de $M$. glomerata pode ser usado de forma segura por humanos, uma vez que não induziu mudanças de importância clínica no perfil hematológico e bioquímico, bem como apresentou valor seguro de DL50, segundo Crowl (1995).

Os ensaios pré-clínicos realizados são

Rev. Bras. PI. Med., Campinas, v.16, n.3, supl. I, p.670-678, 2014. 
TABELA 3. Parâmetros hematológicos de camundongos Swiss, tratados com o extrato etanólico de M. glomerata por via oral durante 30 dias.

\begin{tabular}{lcccc}
\hline Parâmetros & $\begin{array}{c}\text { Controle } \\
(\mathbf{n}=\mathbf{1 0})\end{array}$ & $\begin{array}{c}\text { MG 200 } \\
(\mathbf{n}=\mathbf{1 0})\end{array}$ & $\begin{array}{c}\text { MG 300 } \\
(\mathbf{n}=\mathbf{1 0})\end{array}$ & $\begin{array}{c}\text { MG 400 } \\
(\mathbf{n}=\mathbf{1 0})\end{array}$ \\
\hline Hemácias $\left(\mathrm{mm}^{3}\right)$ & $8,22 \pm 0,24$ & $8,18 \pm 0,32$ & $8,11 \pm 0,28$ & $8,54 \pm 0,25$ \\
Hemoglobina $(\mathrm{g} \mathrm{dL}-1)$ & $13,36 \pm 0,05$ & $12,12 \pm 0,54$ & $12,44 \pm 0,54$ & $14,09 \pm 0,51$ \\
Hematócrito $(\%)$ & $41,24 \pm 1,32$ & $40,46 \pm 1,75$ & $41,44 \pm 1,72$ & $39,81 \pm 1,62$ \\
VCM (fL) & $49,67 \pm 0,04$ & $58,90 \pm 2,56$ & $60,50 \pm 3,02$ & $56,20 \pm 1,08$ \\
HCM (pg) & $16,64 \pm 0,03$ & $24,28 \pm 1,20$ & $24,27 \pm 0,82$ & $22,69 \pm 1,37$ \\
CHCM (\%) & $35,93 \pm 0,38$ & $37,01 \pm 1,04$ & $37,16 \pm 1,11$ & $35,84 \pm 0,50$ \\
Plaquetas (mm $\left.{ }^{3}\right)$ & $442,40 \pm 27,07$ & $442,90 \pm 20,31$ & $440,40 \pm 17,76$ & $442,40 \pm 16,17$ \\
Leucócitos totais $\left(\mathrm{mm}^{3}\right)$ & $4,92 \pm 0,33$ & $4,73 \pm 0,54$ & $4,78 \pm 0,50$ & $4,14 \pm 0,28$ \\
Neutrófilos (\%) & $16,60 \pm 0,88$ & $17,38 \pm 1,33$ & $17,28 \pm 1,14$ & $17,11 \pm 1,16$ \\
Eosinófilos (\%) & $0,35 \pm 0,01$ & $0,00 \pm 0,00$ & $0,00 \pm 0,00$ & $0,00 \pm 0,00$ \\
Linfócitos $\%)$ & $73,99 \pm 2,60$ & $71,00 \pm 3,48$ & $70,10 \pm 2,84$ & $77,10 \pm 2,54$ \\
\hline
\end{tabular}

Legenda: Parâmetros hematológicos obtidos de camundongos machos Swiss, tratados por via oral com solução salina $0,9 \%$ (Controle, $n=$ 10) e com extrato etanólico de M. glomerata (MG) nas doses $200 \mathrm{mg} \mathrm{kg}^{-1}$ (MG 200, $n=10$ ), $300 \mathrm{mg} \mathrm{kg}^{-1}$ (MG 300, $n=10$ ) e 400 mg kg-1 (MG $400, n=10)$ durante 30 dias. Os valores representam a média \pm E.P.M. do número de animais usados nos experimentos. $n-$ representa o número de animais em cada grupo. ap $<0,05$, quando comparados ao grupo controle (ANOVA e teste $t$-Student-Newman-Keuls como post hoc teste);

TABELA 4. Análise morfológica macroscópica de camundongos Swiss, tratados com extrato etanólico de $M$. glomerata por via oral durante 30 dias.

\begin{tabular}{ccccc}
\hline Órgãos & $\begin{array}{c}\text { Controle } \\
(\mathbf{n = 1 0})\end{array}$ & $\begin{array}{c}\text { MG 200 } \\
(\mathbf{n = 1 0})\end{array}$ & $\begin{array}{c}\text { MG 300 } \\
(\mathbf{n}=\mathbf{1 0})\end{array}$ & $\begin{array}{c}\text { MG 400 } \\
(\mathbf{n = 1 0})\end{array}$ \\
\hline Coração & $0,10 \pm 0,00$ & $0,10 \pm 0,00$ & $0,10 \pm 0,00$ & $0,11 \pm 0,00$ \\
Fígado & $0,82 \pm 0,01$ & $0,79 \pm 0,00$ & $0,81 \pm 0,01$ & $0,82 \pm 0,01$ \\
Baço & $0,07 \pm 0,00$ & $0,08 \pm 0,00$ & $0,07 \pm 0,00$ & $0,08 \pm 0,00$ \\
Rim & $0,11 \pm 0,00$ & $0,10 \pm 0,00$ & $0,11 \pm 0,00$ & $0,10 \pm 0,01$ \\
Cérebro & $0,15 \pm 0,00$ & $0,15 \pm 0,01$ & $0,16 \pm 0,00$ & $0,16 \pm 0,00$ \\
Pulmão & $0,15 \pm 0,00$ & $0,15 \pm 0,00$ & $0,15 \pm 0,00$ & $0,15 \pm 0,00$ \\
\hline
\end{tabular}

Legenda: Análise morfológica macroscópica de camundongos Swiss, tratados por via oral com solução salina $0,9 \%($ Controle, $n=10)$ e com extrato etanólico de M. glomerata nas doses $200 \mathrm{mg} \mathrm{kg}^{-1}$ (MG 200, $n=10$ ), $300 \mathrm{mg} \mathrm{kg}^{-1}$ (MG 300, $n=10$ ) e $400 \mathrm{mg} \mathrm{kg}^{-1}$ (MG 400, $n=10$ )

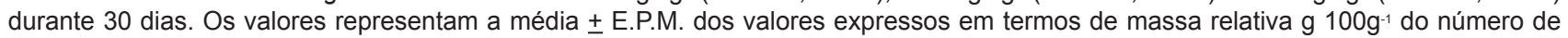
animais usados nos experimentos. $\mathrm{n}$ - representa o número de animais em cada grupo. As vísceras foram cuidadosamente removidas após a eutanásia por aprofundamento de anestesia etéria. Em seguida, dissecadas e determinada suas massas úmidas em balança analítica. ap $<0,05$, quando comparados ao grupo controle (ANOVA e teste $t$-Student-Newman-Keuls como post hoc teste);

importantes para garantir a segurança e eficácia do extrato nas doses testadas (200, 300 e $400 \mathrm{mg}$ $\left.\mathrm{kg}^{-1}\right)$, visto que os animais não apresentaram sinais clínicos de toxicidade durante o tratamento com esse extrato.

$\mathrm{Na}$ literatura consultada junto a bases de dados de patente, verificou-se que extratos preparados a partir da M. glomerata são geralmente empregados no tratamento de doenças respiratórias em humanos. Podem ser citados, como exemplo, o pedido de registro de patente PI 9903296-1, que descreve um processo para obtenção de frações a partir do extrato hidro-alcoólico de folhas de Mikania glomerata com atividade dilatadora da musculatura lisa respiratória, anti-edema e anti-alérgica. Outro pedido de patente encontrado se refere a formulação de xarope feito à base de guaco em associação com outras plantas, sendo indicada para auxiliar no tratamento de bronquite, tosse e como expectorante, especialmente para fumantes.

De acordo com o presente estudo de avaliação das propriedades físico-químicas do pó obtido a partir das folhas de $M$. glomerata sugerese que o pó possa ser usado na formulação de uma forma farmacêutica sólida, bem como que o extrato etanólico possa ser usado de forma segura em humanos, pois não produziu nenhuma alteração morfológica nos principais órgãos e em parâmetros bioquímicos e hematológicos de camundongos.

Com base nos dados citados, bem como por meio de outros dados do mesmo grupo de pesquisa informa-se que este solicitou pedido 
de registro de patente para o extrato estudado intitulado: "Formulações farmacêuticas a partir do extrato etanólico das folhas de Mikania glomerata Sprengel", o qual encontra-se em fase final de avaliação.

\section{REFERÊNCIA}

AULTON, M.E. Delineamento de formas farmacêuticas. Porto Alegre: Artmed, 2005.

BERTOLUCCI, S.K.V. Isolation and HPLC quantitation of kaurane-type diterpenes and cinnamic acid derivatives of long-term stored leaves of Mikania laevigata and Mikania glomerata. Anais da Academia Brasileira de Ciências. v.85, n.2, p. 473-485, 2013.

BREMER, K. Asteraceae. Cladistics and Classification. Portland, Oregon: Timber Press, 1994.752p.

BOTSARIS, A.S. Plants used traditionally to treat malaria in Brazil: the archives of Flora Medicinal. Journal Ethnobiology Ethnomedicine, v.1, p.13-18, 2007.

CARDOSO, M.LC. Desenvolvimento de metodologias analíticas e tecnológica na obtenção de extratos secos nebulizados de Heteropteris afrodisíaca 0. Madi. O - Malpighiaceae. 2002. 128p. Tese (Doutorado em Ciências Farmacêuticas) - Faculdade de Ciências Farmacêuticas, Universidade Estadual Paulista, Araraquara.

CELEGHINI, M.S. et al. Extraction and quantative HPLC analysis of coumarin in hydroalcoholic extracts of Mikania glomerata Sprengel "guaco" leaves. Journal of the Brazilian Chemical Society, v.12, p.706-09, 2001.

CUNHA, C.L. et al. Avaliação da toxicidade aguda e subaguda, em ratos, do extrato etanólicodas folhas e do látex de Synadenium umbellatum Pax. Revista Brasileira de Farmacognosia, v.19, n.2A, p.403-11, 2009.

CROWL, D.A. Introduction Toxic and Highly toxic Chemicals. In: Stanley S.G. and Daniel A.C. Handbook of highly toxic materials handling and management, 1a ed., Chapter 1, Marcel Dekker Inc. New York, USA, 1995.

DO AMARAL, R.R. et al. Avaliação da atividade iMAO e anti-bacteriana de extratos de Mikania glomerata Sprengel. Revista Brasileira de Farmacognosia, v.13, p.24-27, 2003.

FAILACE, R. Hemograma; Manual de Interpretação. 5a ed., Porto Alegre: Artes Médicas, 2009. 424p.

FALCÃO, H.S. et al. Review of the plants with anti-infl ammatory activity studied in Brazil. Revista Brasileira de Farmacognosia, v.15, p.381-91, 2005.

FARMACOPEIABRASILEIRA. 4a Ed. São Paulo: Atheneu, 1988.

FIERRO, I.M. et al. Studies on the anti-allergic activity of Mikania glomerata. Journal of Ethnopharmacology, v.66, p.19-24, 1999.

GRAÇA, C. Determinação da toxicidade pré-clínica do xarope de guaco (Mikania laevigata Schultz Bip. Ex Baker) em roedores. 2004. 116p. Dissertação (Mestrado em Ciências Farmacêuticas) Ciências da Saúde, Universidade Federal do Paraná, Curitiba.

FLECKNELL, P. Laboratory Animal Anesthesia. 2ª ed.
New York: Academic Press, 1996. 274p.

GUO, A. et al. A simple relationship between particle shape effects and density, flow rate and hausner ratio. Powder Technology, v.43, p.279-284, 1985.

HOLETZ, F.B. et al. Screening of some plants used in the brazilian folk medicine for the treatment of infectious diseases. Memórias do Instituto Oswaldo Cruz, v.97,p.1027-31, 2002.

IATSYNO, A.I. et al. Pharmacology of Calenduloside B - A new terpene glycoside obtained from the roots of Calendula officinalis. Farmakologiia i toksikologiia, v.41, p.550-60, 1978.

$\mathrm{KOHN}, \mathrm{D} . \mathrm{F}$. et al. Anesthesia and Analgesia in Laboratory Animals. ACLAM, Academic Press, New York. 1997. 426p.

MAIORANO, A.V. et al. Antiophidian properties of the aqueous extract of Mikania glomerata. Journal of Ethnopharmacology, v.102, p.364-70, 2005.

MALONE, M.H., ROBICHAUD, R.C. A Hippocratic screen for pure or crude drug materials. Lloydia, v.25, p.32032, 1962.

OLIVEIRA, F. Contribuição para o estudo botânico de Mikania hirsutissima DC. var hirsutissima. II Morfologia externa e anatomia da folha, flor, fruto e semente. Revista de Farmácia e Bioquímica, v.10, p.15-36, 1972.

OLIVEIRA, F. et al. Isolamento e identificação de componentes químicos de Mikania glomerata Sprengel e de Mikania laevigata Schultz Bip, ex Baker. Revista de Farmácia e Bioquímica, v.20, n.2, p.169-83, 1984.

PANIZZA, S. Plantas que Curam: cheiro de mato. $25^{\circ}$ ed. São Paulo: IBRASA, 1997. 280p.

$\mathrm{PIO}$ CORREA, M. Dicionário das plantas úteis do Brasil e das exóticas cultivadas. $2^{\circ}$ ed., Rio de Janeiro, 1984. $707 p$.

PRESCOTT, J.K. \& BARNUM, R.A. Sobre a fluidez de pós. Pharmaceutical Technology, v.4, n.6, p.16-30, 2000.

RITTER, M.R. \& MIOTTO, S.T.S. Taxonomia de Mikania Willd. (Asteraceae) no Rio Grande do Sul, Brasil. Hoehnea, v.32, p. 309-59, 2005.

SÁ, R.C.S. Evaluation of long-term exposure to Mikania glomerata (Sprengel) extract on male Wistar rats' reproductive organs, sperm production and testosterone level. Contraception, v.67, p. 327-31, 2003.

SALGADO, H.R.N. et al. Antidiarrhoeal effects of Mikania glomerata Spreng. (Asteraceae) leaf extract in mice. Revista Brasileira de Farmacognosia, v.15, p. 20508, 2005.

SANTANA, L.C.L.R. et al. Avaliação do potencial antioxidante, atividade antimicrobiana e antihelmíntica do extrato etanólico padronizado das folhas de Mikania glomerata Sprengel. Revista Brasileira de Farmácia. v.94, n. 2, p. 120-129, 2013.

SANTANA, L.C.L.R. et al. Avaliação do efeito ansiolítico do extrato etanólico padronizado das folhas de Mikania glomerata Spreng. Revista Brasileira de Ciências Farmacêuticas Básica e Aplicada, 2013 - in press.

SANTOS, S.C. et al. LC characterisation of guaco medicinal extracts, Mikania laevigata and M. glomerata, and their effects on allergic pneumonitis. Planta Medica, v.72, n.8, p.679-84, 2006.

SOARES, M.R. et al. Bronchodilator activity of Mikania glomerata Sprengel on human bronchi and guinea-pig

Rev. Bras. PI. Med., Campinas, v.16, n.3, supl. I, p.670-678, 2014. 
trachea. Journal of Pharmacy and Pharmacology, v.54, p.249-56, 2002.

STANIFORTH, J.N. Fluxo de pós. In: AULTON, M. E., (Ed.). Delineamento de formas farmacêuticas. 2a ed. Porto Alegre: Artmed, 2005. 208-221p.

TALEB-CONTINI, S.H. et al. Differences in secondary metabolites from leaf extracts of Mikania glomerata Sprengel obtained by micropropagation and cuttings. Revista Brasileira Farmacognosia, v.16, p.596-98, 2006.

TESKE, M. \& TRENTINI, A.M.M. Herbarium Compêndio de Fitoterapia. 3a ed. Herbarium, Curitiba, PR. p.160, 1997. 317p.

The United States Pharmacopeia, 30th ed. Rockville: United States Pharmacopoeial Convention, 2007.

VENEZIANI, R.C.S. \& OLIVEIRA, D.C.R. Constituents of Mikania glomerata. Biochemical Systematics and Ecology, v.27, n.1, p.99-102, 1999.

WANCZINSKI, B.J. et al. Desenvolvimento de comprimidos de AAS 500 mg: influência do Amido 1500 ${ }^{\circledR}$ na compressão direta. Acta Scientiarum. v.24, n.3, p.649655, 2002.

Rev. Bras. PI. Med., Campinas, v.16, n.3, supl. I, p.670-678, 2014. 